\title{
Measuring Time-Varying Economic Fears with Consumption-Based Stochastic Discount Factors
}

\author{
Belén Nieto \\ (University of Alicante) \\ and \\ Gonzalo Rubio \\ (University of the Basque Country and University Pompeu Fabra)
}

April $2007^{1}$

Key words: stochastic discount factor, economic fears, distance between probability measures, volatility of stochastic discount factor, consumption

JEL: G10, G12, E44

1/ Belén Nieto (belen.nieto@ua.es) acknowledge financial support from MEC research grant SEJ200509372/ECON and the University of Alicante grant GRJ06-13 and Gonzalo Rubio (gonzalo.rubio@upf.edu, gonzalo.rubio@ehu.es) acknowledge financial support from MEC SEJ200503924/ECON.

Corresponding author: Belén Nieto, Departamento de Economía Financiera, Universidad de Alicante, San Vicente del Raspeig, Alicante, Spain (34-965903400) 


\begin{abstract}
This paper analyzes empirically the volatility of consumption-based stochastic discount factors as a measure of implicit economic fears by studying its relationship with future economic and stock market cycles. Time-varying economic fears seem to be well captured by the volatility of stochastic discount factors. In particular, the volatility of recursive utility-based stochastic discount factor with contemporaneous growth explains between 9 and 34 percent of future changes in industrial production at short and long horizons respectively. They also explain ex-ante uncertainty and risk aversion. However, future stock market cycles are better explained by a similar stochastic discount factor with long-run consumption growth. This specification of the stochastic discount factor presents higher volatility and lower pricing errors than the specification with contemporaneous consumption growth.
\end{abstract}




\section{Introduction}

It is well known that risk-neutral probabilities may be interpreted as objective (or physical) probabilities adjusted upward if they are associated with states in which additional wealth is highly valued and downward if they correspond to states in which more wealth is relatively less valued. Hence, objective probabilities are just risk-neutral probabilities multiplied by some risk aversion adjustment which depends on the actual preferences of the representative investor. The interaction of these two sets of probabilities as a way of measuring time-varying aggregate economic fears is the focus of this work.

When the market is dynamically complete it is well known that the risk-neutral density can be recovered from the corresponding option prices using the insights on Breeden and Litzenberger (1978). In particular, the risk-neutral density is proportional to the second derivative of the option pricing function with respect to the exercise. In practice, however, there is no a continuum of exercise prices. Neither very low nor high exercises are available and, in any case, they are set at discrete intervals by market officials. This complicates the estimation of risk-neutral densities and, not surprisingly, numerous both parametric and nonparametric alternative procedures have been proposed in literature.

On the other hand, the existence of risk aversion means that risk-neutral densities will probably differ from the actual density from which realizations of returns are drawn. The available empirical evidence shows that this is indeed the case. Anagnou, Bedendo, Hodges and Tompkins (2005) for the UK option market, Craig, Glatzer, Keller and Scheicher (2003) for the German stock option data, Bliss and Panigirtzoglou (2004) for the US and the UK option data, and Alonso, Blanco and Rubio (2006) for Spanish option prices conclude that the risk-neutral density is not an unbiased estimator of actual probability density function. As pointed out above, this may not be surprising given the risk-neutrality embedded in these estimates. In other words, these papers suggest that the forecasting differences arise from the risk aversion of the representative investor. In fact, when forecasting through risk-adjusted densities, Bliss and Panigirtzoglou (2004), Alonso, Blanco and Rubio (2006), Shackleton, Taylor and Yu (2006) and Kang and Kim (2006) show that the predicting performance is statistically improved. Hence, these papers are able to recover implied preference parameters from option pricing data and, 
consequently, the equity risk premium and other characteristics describing the differences between both probability measures over time.

In this paper, we do not rely on option pricing data. Santa-Clara and Yan (2005) conclude that ex-ante perceived risk embedded in US option prices far exceed any level of reasonable risks. Under a different framework and using Spanish data, Alonso, Blanco and Rubio (2006) show that an investor with sample average relative risk aversion and realized market volatility requires a 10.2 percent risk premium. On the other hand, depending upon the stochastic discount factor imposed in their estimations, the perceived ex-ante risk premium ranges between 11.5 percent for the power case to 12.5 percent for the time-varying risk aversion as a function of current implied volatility. These are between 12 and 18 percent higher than the risk premium necessary to compensate the same investor for the realized volatility of the Spanish market. Hence, option prices may implicitly contain a higher risk than the one required by a similar investor for realized volatility. For this reason, this paper explores empirically the theoretical results underlying objective and risk-neutral probabilities without relying on option data.

In a recent theoretical paper, Bakshi, Chen and Hjalmarsson (2004) (BCH hereafter) establish a distance between the risk-neutral and the objective probability measures. This distance is defined as the sum over all possible events of the absolute difference between the risk-neutral and the objective probability measures. Interestingly, they are able to propose a lower bound on this distance which is related to the volatility of the stochastic discount factor (SDF). This paper analyzes empirically the volatility of SDFs as a way of capturing economic fears by studying its association with future economic cycles.

There are well known economic episodes, like the stock market crash in 1987, the Asian currency crisis during the summer of 1997, the Russian default in the summer of 1998, the Gulf wars or the terrorist attack on September 11th, 2001, in which the left-tail of the risk-neutral density becomes considerably fatter than the corresponding left-tail of the risk-adjusted counterpart. These crash fears may cause a larger gap or distance in the $\mathrm{BCH}$ sense and, therefore, a higher volatility in any empirically sound SDF. 
A key principle of asset pricing theory is that a risk-neutral distribution that is sufficiently different from its objective distribution is necessary to explain well known facts associated with equity returns. In other words, a highly counter-cyclical marginal utility of aggregate consumption is the main characteristic that any reasonable SDF must display. Hence, following the logic of the $\mathrm{BCH}$ distance metric, at the beginning of stressed economic periods, the volatility of reasonable SDFs should increase to reflect the larger gap between the risk-neutral and objective probability measures.

We employ several SDF candidates and discuss whether they are able to capture timevarying economic fears by estimating their volatilities over time. Thus, we establish an empirical link between the ex-ante economic fears about macroeconomic fundamentals and the ex-post economic cycle in the financial market and the economy. The empirical exercise is performed using data from Spain, one of the largest industrial economies in Europe. Moreover, a robustness analysis of the results using data from the better-known US market is also performed.

The paper shows that recursive preferences and long-run aggregate consumption risk are important when measuring time-varying economic fears. The volatility of the SDF based on recursive preferences and contemporaneous consumption growth tends to be especially high just before macroeconomic recessions, while the volatility of SDFs based simultaneously on long-run consumption growth and recursive preferences seems to be particularly high before persistent decreases in the stock market. The volatility of a habit-based SDF is also significant when predicting both macroeconomic recessions and stock market falls at short-horizons. Interestingly, the recursive utility-based SDFs are also able to explain significantly uncertainty and risk aversion in the stock market.

This paper is organized as follows. Section 2 discusses the theoretical framework that relates risk-neutral and objective probability distributions. Section 3 presents the stochastic discount factor specifications analyzed in the paper, while Section 4 reports the initial empirical results on the lower bound on the distance between both probability measures. Section 5 selects the appropriate consumption-based stochastic discount factors, and Section 6 discusses how well these specifications capture macroeconomic and stock market recessions. Section 7 discusses additional results using US data, and Section 8 concludes with a summary of our findings. 


\section{A Distance Metric between the Risk-Neutral and Objective Probability Distributions}

BCH (2004) study the relationship between risk-neutral and objective densities. They propose an economically sensible distance-metric that captures the dichotomy between both measures and has a natural interpretation in the standard asset pricing framework.

In order to describe their metric, let $\pi$ and $\pi^{*}$ be the objective and risk neutral probability measures associated with the objective density function and the risk-neutral density function, respectively. It is well known that these two measures are probabilistically equivalent since they share exactly the same null events, yet assign different (positive) probability masses to the same events. BCH define the distance between $\pi$ and $\pi^{*}$ as

$$
D_{0}\left(\pi, \pi^{*}\right) \equiv \sum_{i=1,2, \cdots}\left|\pi^{*}\left(A_{i}\right)-\pi\left(A_{i}\right)\right|
$$

which, of course, equals zero if and only if $\pi$ and $\pi^{*}$ assign the same probability mass to every given event $A_{i} \in \mathfrak{I}$, where $\mathfrak{I}$ is the corresponding sigma-field in the state space $\Omega$. They scale $D_{0}\left(\pi, \pi^{*}\right)$ by $\frac{1}{R_{f}}$, where $R_{f}$ is the gross risk-free rate, and they define $D_{1}\left(\pi, \pi^{*}\right) \equiv \frac{1}{R_{f}} D_{0}\left(\pi, \pi^{*}\right)$.

Given that $D_{1}$ is as large as the supreme of the observed pricing errors arising from risk-neutral valuation rather than the objective valuation, and defining

$$
D_{2}\left(\pi, \pi^{*}\right)=\left\|M-\frac{1}{R_{f}}\right\|
$$

where $\|$.$\| is the standard mean-squared norm, and M$ is an stochastic discount factor which belongs to the feasible set of stochastic discount factors ${ }^{1}$, BCH (2004) show that, in an arbitrage-free economy, the following holds:

\footnotetext{
${ }^{1}$ That is, $P(x)=E(M x)$, for every $x \in X$.
} 


$$
D_{1}\left(\pi, \pi^{*}\right) \geq D_{2}\left(\pi, \pi^{*}\right)
$$

Since $E(M)=1 / R_{f}$,

$$
D_{2}\left(\pi, \pi^{*}\right)=\left\|M-\frac{1}{R_{f}}\right\|=\|M-E(M)\|=\sigma(M),
$$

where $\sigma(M)$ is the standard deviation of the stochastic discount factor $M$. In words, the volatility of the stochastic discount factor provides a lower bound for the distance between the risk-neutral and objective probability distribution, up to a constant of proportionality. Hence, their theoretical result derives a measure that characterizes the distance between the risk-neutral and the objective probability measures for any candidate asset pricing model or stochastic discount factor. Unfortunately, their result only provides an estimate of the lower bound on the distance, and not a point estimate. Therefore, in any empirical application we cannot establish whether the actual distance shifted when the lower bound shifted. From an intuitive point of view, recalling the importance of a sufficiently volatile intertemporal marginal utility of aggregate consumption to explain equity premium levels, their result also suggest that, especially in recessions, we should look for a risk-neutral distribution that is sufficiently different from the underlying objective distribution when explaining equity expected excess returns.

The same result can be obtained in terms of the Hansen and Jagannathan (1991) bound. It is well known that the volatility of the stochastic discount factor satisfies the following relation:

$$
\sigma(M) \geq\left[(1-E(M) E(R))^{\prime} \Sigma^{-1}(1-E(M) E(R))\right]^{1 / 2}
$$

where 1 and $R$ are the $N$-vector of one and returns respectively, and $\Sigma$ is the variancecovariance matrix of returns.

Finally, multiplying by $R_{f}$, the following expression on the distance between the riskneutral and the objective probability measures must hold, 


$$
D_{0}\left(\pi, \pi^{*}\right) \geq R_{f}\left[(1-E(M) E(R))^{\prime} \Sigma^{-1}(1-E(M) E(R))\right]^{1 / 2}
$$

Therefore, the Hansen-Jagannathan bound is the minimum distance between the riskneutral and the objective probability measure, which is compatible with observed asset returns. Thus, the magnitude of the volatility of the stochastic discount factor provides a measure of how crash fears are incorporated into asset prices. An increase in the volatility of the discount factor is associated with an increase in the distance between the risk-neutral and the objective probability measure.

\section{Stochastic Discount Factors}

Despite the fact that nondurable consumption growth betas have repeatedly failed to explain the cross-sectional variation of average returns, the recent US and Spanish evidence has shown that the covariance of returns with consumption growth over the quarter of the return and many following quarters explains a considerable variation of expected returns ${ }^{2}$. The main reason is that consumption is slow to adjust to returns. This is a very important result of the modern asset pricing literature because it maintains consumption as a primary determinant of the utility function of the representative agent.

At the same time, in a completely different setting, it has also recently been shown that small and value firms are more pro-cyclical than large and growth firms with respect to the growth rate of durable consumption ${ }^{3}$. This suggests that durable versus nondurable consumption growth rates is a pro-cyclical state variable that accentuates the countercyclical behavior of marginal utility. Moreover, the inclusion of durable consumption can be done under recursive utility where the return of market equity wealth is part of the stochastic discount factor. Once again, this allows a higher volatility of the stochastic discount factor relative to specifications where only consumption growth is employed ${ }^{4}$.

Finally, habit persistence has shown to be a key preference representation in asset pricing modeling ${ }^{5}$. The reason is, of course, associated with the extra volatility in

\footnotetext{
${ }^{2}$ See Parker and Julliard (2005) and Márquez and Nieto (2006) for the US and Spanish markets respectively.

${ }^{3}$ See Yogo (2006).

${ }^{4}$ See Campbell (1996).

${ }^{5}$ See Campbell and Cochrane (1999), Li (2001) and Chen and Ludvigson (2004).
} 
marginal utility of consumption obtained throughout the behavior of the so called surplus consumption ratio which is the percentage difference between consumption and the level of habits.

We now briefly discuss the alternative stochastic discount factors (SDF hereafter) employed in this paper.

The well known SDF under power utility is given by

$$
M_{t+1}=\beta \frac{U^{\prime}\left(C_{t+1}\right)}{U^{\prime}\left(C_{t}\right)}=\beta\left(\frac{C_{t+1}}{C_{t}}\right)^{-\gamma}
$$

where $C_{t}$ is aggregate per-capita non-durable consumption as calculated in time $t$, $U^{\prime}\left(C_{t}\right)$ is marginal utility, $\beta$ is the subjective discount factor or impatience parameter, and $\gamma$ is the coefficient of relative risk aversion. The set of parameters to be estimated is given by $\theta=\{\beta, \gamma\}$.

Parker and Julliard (2005) keep marginal utility of consumption as the key aggregate risk factor. They argue that consumption growth rates and stock returns do not covary contemporaneously as preferences in (7) indicate because agents' consumption takes time to respond to changes in wealth. The cost of adjusting consumption to current circumstances is greater than the cost of adjusting investment in financial assets. Furthermore, marginal utility of consumption is related to other slow-adjusting factors such as changes in labor earnings or property investments. Hence, they suggest measuring asset risk as the covariance between returns and consumption growth rate not only in the period to which returns refer, but also in several periods forward. They refer to this as ultimate consumption risk. They propose the following SDF

$$
M_{t+1}^{S}=\beta^{S+1} \frac{R_{f t+1, t+1+S} U^{\prime}\left(C_{t+1+S}\right)}{U^{\prime}\left(C_{t}\right)}
$$

And, under the power specification, the SDF takes the form

$$
M_{t+1}^{S}=\beta^{S+1} R_{f t+1, t+1+S}\left(\frac{C_{t+1+S}}{C_{t}}\right)^{-\gamma}
$$


where $C_{t+1+S} / C_{t}$ is the consumption growth rate between $t$ and $t+1+S$, and $R_{f t+1, t+1+S}$ is the risk-free rate corresponding to the same horizon. In the empirical specification below, we follow the finding of Márquez and Nieto (2006) who verify that a three-year frame ( $S$ is 11 quarters) is the most appropriate time lag for conciliating the consumption growth rate with current returns on equity assets in the Spanish case ${ }^{6}$.

Contrary to the previous specifications, the SDF under recursive utility has the advantage of separating relative risk aversion and the elasticity of intertemporal substitution. Moreover, this SDF not only incorporates consumption growth but also the return on the market portfolio. In particular, under recursive utility, the contemporaneous SDF is given by,

$$
M_{t+1}=\left[\beta\left(\frac{C_{t+1}}{C_{t}}\right)^{-1 / \eta}\right]^{\kappa} R_{m t+1}^{\kappa-1}
$$

where $\eta$ is the elasticity of intertemporal substitution, $\kappa \equiv \frac{1-\gamma}{1-1 / \eta}$, and $R_{m t}$ is the return on the market portfolio at any time $t$. The set of parameters to be estimated is given by $\theta=\{\beta, \gamma, \eta\}$.

Similarly, the specification under ultimate consumption risk and recursive utility becomes,

$$
M_{t+1}^{S}=\left[\beta^{S+1}\left(\frac{C_{t+1+S}}{C_{t}}\right)^{-1 / \eta}\right]^{\kappa} R_{m t+1+S}^{\kappa-1} R_{f t+1+S}
$$

Yogo (2006) incorporates durable consumption to the marginal utility using a recursive preferences specification in which both types of consumption are not separable. The idea is, as usual, to increase the volatility of marginal consumption. The contemporaneous SDF is given by,

\footnotetext{
${ }^{6}$ Somewhat surprisingly, the same time lag is found by Parker and Julliard with US data.
} 
$M_{t+1}=\left[\beta\left(\frac{C_{t+1}}{C_{t}}\right)^{-1 / \eta}\left(\frac{1-\alpha+\alpha\left(D_{t+1} / C_{t+1}\right)^{(\rho-1) / \rho}}{1-\alpha+\alpha\left(D_{t} / C_{t}\right)^{(\rho-1) / \rho}}\right)^{(\eta-\rho) /(\eta(\rho-1))} R_{m t+1}^{1-1 / \kappa}\right]^{\kappa}$

where $D_{t}$ is aggregate per-capita stock of durable consumption as calculated in time $t$, $\alpha$ is the expenditure share of the durable consumption good, and $\rho$ is the elasticity of substitution between durable and non-durable consumption. Hence, the set of parameters is given by $\theta=\{\beta, \gamma, \eta, \alpha, \rho\}$.

As before, this paper analyzes the durable consumption-based asset pricing model under the perspective of ultimate consumption risk. In this case, the SDF becomes,

$$
M_{t+1}^{S}=\left[\beta^{S+1}\left(\frac{C_{t+1+S}}{C_{t}}\right)^{-1 / \eta}\left(\frac{1-\alpha+\alpha\left(D_{t+1+S} / C_{t+1+S}\right)^{(\rho-1) / \rho}}{1-\alpha+\alpha\left(D_{t} / C_{t}\right)^{(\rho-1) / \rho}}\right)^{(\eta-\rho) /(\eta(\rho-1))}\right]^{\kappa}
$$

Finally, the SDF under the external habit persistence model of Campbell and Cochrane (1999) is given by,

$$
M_{t+1}=\beta\left(\frac{S C_{t+1}}{S C_{t}} \frac{C_{t+1}}{C_{t}}\right)^{-\gamma}
$$

where $H_{t}$ is the level of habits and $S C_{t}=\frac{C_{t}-H_{t}}{C_{t}}$ is a state variable known as "surplus consumption ratio" that allows to capture dependencies among states of nature. It is important to note that $S C_{t}$ is a recession indicator; it is low after several quarters of consumption declines and high in booms. It should be noted that the recognition of habits eliminates the need of including long-run consumption growth rates in the SDF. The nature of habits should be playing the equivalent role of ultimate consumption risk.

Under this specification, relative risk aversion changes with the surplus consumption ratio, 


$$
A R\left(S C_{t}\right)=\frac{\gamma}{S C_{t}}
$$

Hence, with recessions, as consumption falls toward habit, people become less willing to tolerate further falls in consumption and they become more risk averse.

Next, we define the habit formation process. Level of habits can be written as a function of past consumption. We use consumption growth rates to ensure that the function is stationary to get

$$
H_{t}=C_{t} g\left(\frac{C_{t-1}}{C_{t}}, \ldots ., \frac{C_{t-L}}{C_{t}}\right)
$$

A reasonable function that guarantees $H_{t}<C_{t}$ is the following:

$$
g(x)=h\left(1+e^{-x}\right)^{-1}
$$

where $h$ is the global habit persistence parameter, $x=\left(\delta \frac{C_{t-1}}{C_{t}}+\delta^{2} \frac{C_{t-2}}{C_{t}}+\ldots .+\delta^{L} \frac{C_{t-L}}{C_{t}}\right)$, and it is verified that $0 \leq g(x) \leq 1$.

Therefore, the habit specification is given by

$$
H_{t}=C_{t} h\left(1+e^{-\left(\delta \frac{C_{t-1}}{C_{t}}+\delta^{2} \frac{C_{t-2}}{C_{t}}+\ldots .+\delta^{L} \frac{C_{t-L}}{C_{t}}\right)}\right)^{-1}
$$

In the actual estimation of this model, and to be consistent with ultimate consumption risk, $L$ will be 12 quarters. The set of parameters to be estimated is $\theta=\{\beta, \gamma, h, \delta\}$.

\section{Measuring the Lower Bound on the Distance between the Risk-Neutral and the Objective Probability Measures over Time}

Our main concern is to estimate the distance between risk-neutral and objective probability distributions over time without relying on option data. 
We have calculated quarterly real data on non-durable and durable Spanish consumption growth from 1962 to 2003. In fact, aggregate annual consumption data are available from 1954 to 2003. The Spanish National Accounts do not distinguish between non-durable and durable consumption; however, there exists a detailed classification of consumption expenditure by type of goods in two alternative sources: Uriel, Moltó and Cucarella (2000) for the 1954-1994 period, and those published in the Spanish National Accounts for the years between 1995 and 2003. We have linked these series including, as non-durable consumption goods and services, the following items: food products, beverages and tobacco; clothing and footwear; household rental, heating and lighting; household entertainment goods and services; medical and healthcare services; maintenance of means of personal transport; use of public transport; communications; entertainment and culture; other goods and services. The following concepts are classified as durable consumption: furnishing, accessories and household goods; purchase of vehicles; articles related to entertainment, sport and culture; books, newspapers and magazines; teaching. In both cases, we use data at constant 1986 prices and the series are adjusted for seasonality.

Unfortunately, disaggregated quarterly data by type of consumption are not available for the Spanish case. We have converted annual into quarterly figures applying the procedure described in Casals, Jerez and Sotoca (2005) ${ }^{7}$.

The nondurable good is entirely consumed in the period of purchase, whereas the durable good provides service flows for more than one period. We compute the quarterly service flow for period $t$, which we denote by $D_{t}$, using the following motion

$$
D_{t}=\sum_{\tau=0}^{48}(1-\tau \delta) E_{t-\tau} \text {, }
$$

where $E_{t}$ is durable consumption expenditure in quarter $t, \delta$ is the quarterly depreciation rate which takes the value of 1.875 percent, that is consistent with the

\footnotetext{
${ }^{7}$ The desegregation has been made following standard state-space techniques. The desegregation employs the information contained in a quarterly instrument and the specific technique is based on the principle of empirical consistency. This implies that, given the aggregation constraint, the models relating the variables in high and low sampling frequencies should be mutually compatible. We use quarterly car registrations published by ANFAC (Spanish Motor Vehicle Manufacturers' Association) as the instrument for computing quarterly durable consumption and the total production of manufactured goods index published by the INE (Spanish Statistics Agency) as an indicator of quarterly non-durable consumption goods. The estimation procedures are implemented in a Matlab toolbox for time series modeling called E4, which can be downloaded at www.ucm.es/info/icae/e4.
} 
depreciation rates of motor vehicles published by the Ministry of Economy and Public Finance. The quarterly service flow series is computed using 48 durable consumption expenditure lags ${ }^{8}$.

Finally, we have real returns on the equally-weighed market portfolio and ten equallyweighted size-sorted portfolios from 1963 to 2003. Moreover, quarterly real interbank rate is used as the risk-free rate between 1963 and 1987. Since then, the real threemonth Treasury bill rate is employed as the proxy for the riskless rate. The consumer price index has been used to deflate all nominal figures.

The Hansen-Jagannathan volatility bound is estimated as expressed in equation (5) with realized returns on the ten size-sorted portfolios and for a range of different values for $E(M)$. Figure 1 displays the feasible region for the SDF implied by the available data from 1963 to 2003. The minimum standard deviation of the SDF associated to the realized mean risk-free rate (1.5 percent quarterly) is about 0.35 , corresponding to a mean SDF of about 0.985. As pointed out above, the volatility of the SDF is the lower bound on the distance between the risk-neutral and objective probability measures.

Figure 2 displays the volatility of the SDF using expression (5) but now overlapping sub-periods of 5 years of quarterly data from ten size-sorted portfolios. Since the riskfree rate is not constant over the whole period, we multiply the H-J volatility bounds by the average risk-free rate for each sub-period to generate lower bounds on the probabilities distance that are comparable across time.

It is interesting to point out that the bound moves quite a lot over time. Note that these are completely model-free estimates of the bound on the distance between both probability distributions. Figure 2 also contains Spanish macroeconomic recession bars in grey and stock market recessions in salmon as identified by a continuous decreasing period in the level of the Spanish stock market index ${ }^{9}$. The stock market recessions tend to be slightly ahead of macroeconomic recessions. As pointed out above, it is clear that there are substantial differences in the distance between the risk-neutral and objective probability measures between 1963 and 2003. This suggests that recession fears, that

\footnotetext{
${ }^{8}$ It must be point out that purchase of vehicles constitutes the principal component of the durable good expenditure. A linear depreciation assumption consisting in a 1.875 percent rate gives the durable good a value of 10 percent after 48 quarters, which concords with the official depreciation rates published by the Ministry. The first observations had to be calculated with a smaller number of lags, since the original data started in 1954.

${ }^{9}$ These are obtained by following the procedure of the National Bureau of Economic Research (NBER).
} 
most likely causes these differences, are time-varying over time. In particular, what is more interesting is to note that the volatility of the SDF (scaled by the risk-free rate) tends to increase in the quarters before or during macroeconomic recessions. Moreover, our results also show that this distance has not experienced a permanent increase after the crash of 1987. It is true that the volatility displays an increase just before October 1987. However, the volatility of the SDF substantially decreased between 1987 and the 1992 recession economic period.

\section{The Estimation of Parameters for Alternative SDF Specifications}

This section selects appropriate parametric SDFs by simulation procedures and using consumption data and stock returns from the Spanish economy. The idea is to study the behavior of the volatility of alternative specifications of consumption-based SDFs. Appropriateness is understood as those SDFs that generate pairs of $E(M)$ and $\sigma(M)$ which enter in the feasible region shown in Figure 1.

All specifications discussed in Section 3 are analyzed here. In particular, we explore the traditional power utility of equation (7), the recursive utility specification of expression (10), the long-run version of recursive utility (recursive long) given by (11), the durable SDF suggested by Yogo (2006) as in equation (12), its long-run version (Yogo long) given by (13), and the habit persistence model described in equations (14) and (18). We also consider a power utility model with both durable and non-durable consumption growth rates. This former specification of the SDF and the traditional power SDF are not able to generate pairs of means and volatilities of $M$ which enter in the HansenJagannathan region. For this reason, we do not discuss the behavior of the volatility of the SDF for any of these two models.

Specifically, for each SDF, we try a large grid of feasible preference parameters. We then select a set of combination of those parameters that generate a volatility of the SDF over the H-J bound of 0.35 . After we compute the pricing error of each of these SDF in valuating the ten size-sorted portfolios returns. Figure 3 displays the ten pricing kernels with the lowest mean-squared pricing errors for each of the five SDF specifications analyzed. 
Finally, we choose, for each SDF specification, the preference parameters that make the SDF to enter inside the feasible mean-volatility space and to comet the lowest error in pricing the ten portfolios. The results are shown in Table 1.

Table 1 contains the parameter estimates, the volatility of $M$, the mean of $M$, and the mean-squared pricing error for each of the five SDFs chosen throughout the empirical exercise. The lowest mean-squared pricing error is obtained for the habit preference specification. However, it should be noted the large volatility and the low mean of $M$ generated by this specification. It is interesting to note that recursive long and Yogo long also have a relatively low mean-squared pricing error, but this success is also accompanied by relatively large volatility and low mean of $M$. On the other hand, the contemporaneous recursive and Yogo models generate a pair of $E(M)$ and $\sigma(M)$ which is very close to the minimum historical figures for feasible SDFs. Unfortunately, the mean-squared pricing error is higher than in the other three cases. In general, habit persistence and long-run consumption growth models have very volatile SDFs and quite low pricing errors. Moreover, the two long-run versions are able to generate these characteristics with very reasonable levels of risk aversion. In fact, both recursive long and Yogo long SDFs have a very similar behavior both on average and over time. It seems that the combination of long-run consumption growth and the inclusion of the market portfolio return in the SDF through recursive preferences are key properties of potentially valid SDFs. Both models adequately capture the business cycle behavior of the economy which probably explains the success in pricing the ten size-sorted portfolio returns.

Figure 4 represents, over time and across recessions, the five SDFs reported in Table 1. In general, all SDFs tend to be high at the very beginning of (or even just before) recessions and low at the end of recessions (beginning of expansions). This is particularly the case for the habit, recursive long and Yogo long specifications. However, as expected, given the estimates reported in Table 1, the habit persistence model displays a very volatile behavior.

Figure 5 displays the volatility of the five SDFs estimated with five years of overlapping data ${ }^{10}$. Once again, it must be pointed out the increasing behavior

\footnotetext{
${ }^{10}$ These volatilities are multiplied by the corresponding risk-free rate over the period.
} 
experienced by the volatility of the SDF for the recursive long and Yogo long cases at the beginning of recessions. This indicates that the distance between risk-neutral and objective probability distributions becomes larger just before or at the beginning of recessions. Therefore, it seems that $\sigma(M)$ for the cases of SDFs with ultimate consumption risk and recursive preferences capture time-varying economic fears of investors. However, more formal tests are necessary before reaching further and more precise conclusions.

\section{Economic Cycles, Financial Market Uncertainty and the Consumption-based Stochastic Discount Factors}

As we have just argued, the volatility of the SDF reflects the distance between the riskneutral and objective probability distributions, which contains economic fears implicit in the investment behavior of investors. If so, the volatility of the SDF not only should contain information about the economic uncertainty, but it should also be able to predict future realized macroeconomic cycles. Both features are analyzed in this section.

The first analysis consists on determining whether the overlapping standard deviation of our five SDF specifications incorporates information about the future of two selected state variables: the growth rate of the industrial production index and the stock market returns.

We therefore perform the following OLS autocorrelation-robust-standard-error regressions for our five alternative SDF specifications:

$$
\frac{I P I_{t+j}-I P I_{t}}{I P I_{t}}=\alpha+\beta \sigma\left(M_{t}\right)+\varepsilon_{t+j}, j=1,2,4,8,12
$$

where $I P I_{t}$ is the quarterly Industrial Production Index for quarter $t$.

A similar regression is run for the market return index,

$$
R_{m t+j}=\alpha+\beta \sigma\left(M_{t}\right)+\varepsilon_{t+j}, j=1,2,4,8,12
$$

The estimation results of regressions (20) and (21) are reported in Panels A and B of Table 2, respectively. Both Panels show that for all specification of the SDF, increases 
in the volatility of the SDF (a larger distance between the risk-neutral and the objective probability measures) is significantly associated with both a recession in the macroeconomic cycle of the Spanish economy and decreasing stock market behaviour. This is consistent with Figures 2 and 5. Moreover, for most cases, the predicting ability of the volatility of SDF increases with the horizon used in regressions. Hence, from an empirical point of view, the volatility of appropriated-selected consumption-based SDFs seems to be a powerful measure of future economic cycles. Larger implicit fears in the stock market seem to be significantly negatively correlated with future changes in industrial production and stock market returns.

Because the volatility of the discount factor is very persistent, we also calculate the bias-corrected estimator and the corresponding bias-corrected $t$-statistic proposed by Amihud and Hurvich (2005). These authors suggest an augmented regression method for hypothesis testing in predictive regressions with multiple autoregressive predictor variables. Their simulations show that their adjustment outperforms other biascorrection methods such as those suggested by Stambaugh (1999) or Lewellen (2004). Although the new $t$-statistics tend to be lower than the ones reported, these adjustments do not change the qualitative conclusions reached throughout the paper.

Interestingly, the largest explanatory power, when forecasting macroeconomic cycles at any horizon, corresponds to the recursive preference specification with contemporaneous consumption. On the other hand, we need to incorporate ultimate consumption risk if we want to explain the future behaviour of stock market returns. This is especially true for longer horizons. It is probably reasonable to recall that SDF specifications with recursive preferences and long-run consumption growth provide a low pricing error and a relatively high volatility of the SDF. In this sense, the results from Panel B of Table 2 are consistent with the evidence reported in Table 1.

The second question is whether the consumption-based SDFs and their volatilities are able to explain forward looking measures of stock market uncertainty and risk aversion. 
As a measure of market uncertainty, we employ the implied volatility of ATM call and put options on the future of the Spanish market stock index. Unfortunately, we only have monthly implied volatilities from October 1996 to December $2004^{11}$.

The difference between the monthly probabilistic mass assigned to the 10 percent left tail of the risk-neutral distribution and the risk-adjusted distribution will be used as a measure of risk aversion. The extreme left-tailed events corresponds to bad states of nature which suggests that this difference should always be positive, since risk-neutral probabilities tend to pay more attention to unpleasant states (states with high marginal utility of consumption) relative to objective probabilities. This is of course the risk adjustment implicit in risk-neutral pricing and can be interpreted as a measure of exante risk aversion. These differences in probabilistic mass are also available only from October 1996 to December 2004. Alonso, Blanco and Rubio (2006) estimate monthly risk-neutral densities from a cross-section of call and put settlement option prices. They are estimated using a mixture of two-lognormals. Imposing a power utility functional form for the SDF, and given the estimated risk-neutral density from option data, Alonso, Blanco and Rubio (2006) estimate the preference (relative risk aversion) parameter that maximize the forecasting ability of the objective density function ${ }^{12}$. The 10 percent left-tailed probabilistic mass is then obtained from their risk-neutral and riskadjusted density functions, and our measure of ex-ante risk aversion is taken as the difference between the two probabilistic masses assigned by both estimated density functions.

Figure 6 displays our two measures of ex-ante uncertainty and risk aversion ${ }^{13}$. The similarities between both variables are striking. It suggests that implied volatility contains information about the distance between these probability measures in the left tail of the distribution. Hence, implied volatility seems to incorporate implicit fears that investors have on potential crashes of the stock market and, consequently, on their risk aversion attitudes. In other words, the difference between both probabilistic masses

\footnotetext{
${ }^{11}$ These data are the same used by Alonso, Blanco and Rubio (2006) when estimating risk-neutral and risk-adjusted densities in the Spanish option market.

${ }^{12}$ Alonso, Blanco and Rubio (2006) explore alternative utility specifications. Interestingly, independently of the stochastic discount factor employed, they cannot reject the hypothesis that risk-adjusted densities provide adequate predictions of the distributions of future realisations of the Spanish market index at four and eight-week horizons. Hence, all risk-adjusted densities generate similar forecasting statistics. In our case, we just take the simplest risk adjustment from the power utility specification.

${ }^{13}$ They are transformed into quarterly figures.
} 
reflects the extra probability associated with unpleasant states of nature. It seems that implied volatility extracted from option prices also contains this extra probability, that is, our evidence suggests that implied volatility reflects risk aversion of market participants.

Despite the fact that we have few observations on these measures, we perform a series of regressions to illustrate whether the SDF specifications and their volatilities are able to explain ex-ante uncertainty and risk aversion. In particular, we run the following OLS autocorrelation-robust-standard-error regressions for our five alternative SDF specifications:

$$
\begin{gathered}
\frac{I V_{t}-I V_{t-1}}{I V_{t-1}}=\alpha+\beta M_{t}+\varepsilon_{t+1} \\
I V_{t}=\alpha+\beta M_{t}+\varepsilon_{t+1} \\
I V_{t}=\alpha+\beta \sigma\left(M_{t}\right)+\varepsilon_{t+1}
\end{gathered}
$$

where $I V_{t}$ is the implied volatility of ATM options at the last month of quarter $t, I V_{t-1}$ is the implied volatility at the last month of the previous quarter, and $M_{t}$ is the stochastic discount factor for quarter $t$.

Moreover, we also run the following regressions,

$$
\begin{gathered}
\frac{L T_{t}-L T_{t-1}}{L T_{t-1}}=\alpha+\beta M_{t}+\varepsilon_{t+1} \\
L T_{t}=\alpha+\beta M_{t}+\varepsilon_{t+1} \\
L T_{t}=\alpha+\beta \sigma\left(M_{t}\right)+\varepsilon_{t+1}
\end{gathered}
$$

where $L T_{t}$ is the difference between the probabilistic mass assigned by the risk-neutral distribution and the risk-adjusted distribution for the 10 percent left-tail at the last month of quarter $t$.

The results from regressions (22), (23) and (24) are reported in Table 3, Panels A, B, and $\mathrm{C}$ respectively. Independently of the specification employed, the results show that 
the recursive SDF and Yogo's specification with contemporaneous consumption are able to explain market uncertainty as measured by implied volatility. Both, the SDF itself and its volatility are positively and significantly related with ex-ante uncertainty.

As expected, given the results from Figure 6, the results using our measure of risk aversion are the same. This evidence is contained in Table 4 with Panels A, B, and C for regressions (25), (26), and (27), respectively.

When trying to explain short-run uncertainty or risk aversion, the simplest recursive utility specification is powerful enough to significantly describe either levels or changes or uncertainty and risk aversion. The caveat is, of course, that we have a very limited time-series of uncertainty and risk aversion measures. In this sense, SDFs with ultimate consumption risk have even less observations. Moreover, these types of specifications clearly capture economic cycles. However, implied volatilities experience pronounced changes from one month to another. This represents a serious difficulty for either habit or ultimate consumption risk-based SDFs when trying to explain uncertainty or risk aversion from one period to another ${ }^{14}$.

\section{A Robustness Analysis using US Market Data}

We use seasonally adjusted quarterly aggregate nominal expenditure on consumer nondurable and services for the period 1962-2003 from National Income and Product Accounts (NIPA). We also take population numbers and price deflator from NIPA to construct the time series of per capita real nondurable consumption numbers for use in this section. On the other hand, durable consumption consists of items such as motor vehicles, furniture and appliances, and jewelry and watches. These are also taken from NIPA and we follow Yogo's procedure to construct the corresponding quarterly time series. The returns on the ten size-sorted portfolios, the risk-free return and the market returns are taken from Kenneth French’s website.

The procedure is exactly the same followed for the Spanish case. First of all, Figure 7 displays the overlapping 5-years sub-periods of the volatility of the SDF estimated by equation (5) ${ }^{15}$. As before, the volatility tends to increase in the quarters before

\footnotetext{
${ }^{14}$ See the related evidence of Beber and Brandt (2006). They find that when there is a lot of ex-ante uncertainty about macroeconomic fundamentals and new data is released, overall uncertainty and implied volatility significantly diminish in the US market.

${ }^{15}$ As in the Spanish case, we multiply the volatility by the average risk-free rate for each sub-period.
} 
macroeconomic recessions as defined by the NBER. Secondly, the consumption-based SDF of section 3 are estimated for the US case. Once again, the smaller pricing errors are for the long-run consumption risk specifications. Interestingly, the habit persistence model displays a pricing error as high as the contemporaneous recursive and durable models. Thirdly, the selected SDFs are displayed in Figure 8, and their volatilities are contained in Figure 9. In both cases, it seems clear that the behavior of the SDFs closely follow the behavior of the Spanish counterparts. Fourthly, the predicting ability of the volatility of the SDFs is not as strong as in the Spanish case. However, once again, the recursive and Yogo specifications have more forecasting ability for macroeconomic recessions, while stock market returns are better captured by the long-run specifications. Finally, uncertainty is measured by the CBOE Volatility Index (VIX) which has become the benchmark for the US stock market volatility. Although the magnitudes of the $R$ squares are again lower than for the Spanish case, the SDFs based on recursive and Yogo specifications also show a better explanatory power than its long-run counterparts. These overall similarities tend to provide a reasonable level of confidence on the results using Spanish data.

\section{Conclusions}

In this paper we measure implicit recession fears of investors by the volatility of appropriated-selected consumption-based SDFs. The SDF specifications with lowest pricing errors and high volatility are reported to have a reasonable predicting ability of future market recessions. In particular, a recursive utility SDF with long-run consumption risk (either with or without durable goods) are able to explain up to a 23.5 percent of future market returns at long horizons. The volatility of the habit-based SDF also has a good forecasting capacity at short horizons. This seems to be related with the extremely high volatility of this SDF.

On the other hand, the SDF specification with recursive preferences and contemporaneous consumption growth, which is characterized by a relatively low volatility, seems to be the most powerful specification in capturing future macroeconomic cycles approximated by changes in the industrial production index. Thus, the volatility of this SDF explains between 9.3 and 34.4 percent of the future macroeconomic growth at short and long horizons respectively. Interestingly, the SDF 
under the recursive-based utility specification also explains up to 40.5 percent of market uncertainty and risk aversion.

Given the results from the robustness analysis using US data, we may conclude that the volatility of consumption-based SDFs seems to be a powerful indicator of both economic and stock market cycles. It suggests a strong connection between financial markets and the real economy which deserves future attention. Extending this work to additional economies and performing truly out-of-sample tests seem to be a promising future avenue of research. 
Alonso, F., Blanco, R. and G. Rubio (2006), Option-Implied Preferences Adjustments, Density Forecasts, and the Equity Risk Premium, Working Paper 0630, Bank of Spain.

Amihud, Y. and C. Hurvich (2004), Predictive Regressions: A Reduced-Bias Estimation Method, Journal of Financial and Quantitative Analysis Vol. 39, 813-841.

Anagnou, I., M. Bedendo, S. Hodges and R. Tompkins (2005), Forecasting Accuracy of Implied and GARCH-based Probability Density Functions, Review of Futures Markets Vol. 11, 41-66.

Bakshi, G., Z. Chen, and E. Hjalmarsson (2004), Volatility of the Stochastic Discount Factor, and the Distinction between Risk-Neutral and Objective Probability Measures, Working Paper, Yale School of Management.

Beber, A. and M. Brandt (2006), Resolving Macroeconomic Uncertainty in Stock and Bond Markets, Working Paper, Fuqua School of Business, Duke University.

Bliss, R. and N. Panigirtzoglou (2004), Option-implied Risk Aversion Estimates, Journal of Finance, Vol. 59, 407-446.

Breeden, D. and R. Litzenberger (1978), Prices of State Contingent Claims Implicit in Option Prices, Journal of Business, Vol. 51, 621-652.

Campbell, J. (1996), Understanding Risk and Return, Journal of Political Economy, Vol. 104, 298-345.

Campbell, J. and J. Cochrane (1999), By Force of Habit: A Consumption-Based Explanation of Aggregate Stock Market Behavior, Journal of Political Economy, Vol. 107, 205-251.

Casals, J., M. Jérez and S. Sotoca (2005), Empirical Modelling of Time Series Sampling at Different Frequencies, Working Paper Series, Universidad Complutense de Madrid, Departamento de Fundamentos del Análisis Económico II.

Chen, X. and S. Ludvigson (2004), Land of Addicts? An Empirical Investigation of Habit-Based Asset Pricing Behavior, Working Paper 10503, National Bureau of Economic Research, Cambridge.

Craig, B., E. Glatzer, J. Keller and M. Scheicher (2003), The Forecasting Performance of German Stock Option Densities, Discussion Paper 17, Studies of the Economic Research Centre, Deutsche Bundesbank.

Kang, B. and T. Kim (2006), Option-implied Risk Preferences: An Extension to Wider Classes of Utility Functions, Journal of Financial Markets Vol. 9, 180-198.

Hansen, L., and R. Jagannathan (1991), Implications of Security Market Data for Models of Dynamic Economies, Journal of Political Economy, Vol. 99, 225-262. 
Lewellen, J. (2004), Predicting Returns with Financial Ratios, Journal of Financial Economics, Vol. 74, 209-235.

Li, Y. (2001), Expected Returns and Habit Persistence, Review of Financial Studies, Vol. 14, 861-899.

Márquez, E. and B. Nieto (2006), Consumption and Asset Pricing: Further International Evidence on Durable Consumption Growth and Long Run Consumption Risk, Working Paper, University of Alicante, Spain.

Parker, J. and C. Julliard (2005), Consumption Risk and the Cross-Section of Expected Returns, Journal of Political Economy, Vol. 113, 185-222.

Santa-Clara, P. and S. Yan (2005), Crashes, Volatility, and the Equity Premium: Lessons from S\&P 500 Options, Working Paper, The Anderson School of Business, University of California at Los Angeles.

Shackleton, M., S. Taylor and P. Yu (2006), A multi-horizon Comparison of Density Forecasts for the S\&P500 Using Index Returns and Option Prices, Working Paper, Department of Accounting and Finance, Lancaster University, England.

Stambaugh, R. (1999), Predictive Regressions, Journal of Financial Economics Vol. 5, 375-421.

Uriel, E., M. Moltó and V. Cucarella (2000), Contabilidad Nacional de España: Series enlazadas 1964-1997, Fundación BBVA, Madrid.

Yogo, M. (2006), A Consumption-Based Explanation of Expected Stock Returns, Journal of Finance, Vol. 61, 539-580. 
Table 1

Estimated Parameters and Moments for Alternative Stochastic Discount Factors with Lowest Pricing Error

1965-2003

\begin{tabular}{|c|c|c|c|c|c|c|c|c|c|c|}
\hline SDF & $\beta$ & $\gamma$ & $\eta$ & $\alpha$ & $\rho$ & $\delta$ & $h$ & $E(M)$ & $\sigma(M)$ & $\begin{array}{c}\text { Pricing } \\
\text { Error }\end{array}$ \\
\hline Recursive & 0.880 & 29 & -0.05 & N.A. & N.A. & N.A. & N.A. & 0.9777 & 0.3561 & 0.2891 \\
\hline $\begin{array}{c}\text { Recursive } \\
\text { Long-Run } \\
\text { Growth }\end{array}$ & 0.925 & 1.5 & -0.05 & N.A. & N.A. & N.A. & N.A. & 0.9263 & 0.5458 & 0.0573 \\
\hline $\begin{array}{c}\text { Yogo } \\
\text { Yogo } \\
\begin{array}{c}\text { Long-Run } \\
\text { Growth }\end{array}\end{array}$ & 0.820 & 25 & -0.05 & 0.85 & 0.95 & N.A. & N.A. & 0.9650 & 0.3893 & 0.1472 \\
\hline \begin{tabular}{c} 
Habit \\
\hline
\end{tabular} & 0.800 & 150 & N.A. & N.A. & N.A. & 0.50 & 0.99 & 0.9285 & 0.8668 & 0.0342 \\
\hline
\end{tabular}

$\beta$ is the subjective discount factor for future period utility; $\gamma$ is the coefficient of relative risk aversion; $\eta$ is the elasticity of intertemporal substitution; $\alpha$ is the expenditure share of the durable consumption good; $\rho$ is the elasticity of substitution between durable and non-durable consumption; $\delta$ is the weight associated with past consumption; $h$ is the global habit persistence parameter; and pricing error is the mean squared error over ten size-sorted portfolios. 
Table 2

\begin{tabular}{|c|c|c|c|c|c|c|c|c|c|c|c|}
\hline \multicolumn{12}{|c|}{$\begin{array}{l}\text { Panel A: Future Industrial Production Index and the Volatility of SDFs } \\
\qquad \frac{I P I_{t+1}-I P I_{t}}{I P I_{t}}=\alpha+\beta \sigma\left(M_{t}\right)+\varepsilon_{t+1}\end{array}$} \\
\hline & & \multicolumn{2}{|c|}{ Recursive } & \multicolumn{2}{|c|}{ Yogo } & \multicolumn{2}{|c|}{ Habit } & \multicolumn{2}{|c|}{$\begin{array}{l}\text { Recursive } \\
\text { Long }\end{array}$} & \multicolumn{2}{|c|}{$\begin{array}{l}\text { Yogo } \\
\text { Long }\end{array}$} \\
\hline \multirow{3}{*}{$\begin{array}{c}1 \\
\text { Quarter }\end{array}$} & Constant & 0.024 & $(4.00)$ & 0.019 & (3.66) & 0.016 & (4.40) & 0.019 & (4.42) & 0.019 & (4.41) \\
\hline & Slope & -0.049 & $(-2.78)$ & -0.039 & $(-2.38)$ & -0.012 & $(-2.53)$ & -0.030 & $(-2.92)$ & -0.030 & $(-2.90)$ \\
\hline & $R^{2}(\%)$ & 9.27 & & 6.73 & & 7.83 & & 7.90 & & 7.95 & \\
\hline \multirow{3}{*}{$\begin{array}{c}2 \\
\text { Quarters }\end{array}$} & Constant & 0.047 & (3.88) & 0.038 & (3.63) & 0.033 & $(4.45)$ & 0.038 & $(4.41)$ & 0.038 & $(4.40)$ \\
\hline & Slope & -0.095 & $(-2.71)$ & -0.077 & $(-2.38)$ & -0.024 & $(-2.66)$ & -0.060 & $(-2.90)$ & -0.058 & $(-2.87)$ \\
\hline & $R^{2}(\%)$ & 16.08 & & 12.07 & & 14.59 & & 13.91 & & 13.99 & \\
\hline \multirow{3}{*}{$\begin{array}{c}4 \\
\text { Quarters }\end{array}$} & Constant & 0.095 & $(3.91)$ & 0.078 & (3.76) & 0.063 & $(4.30)$ & 0.074 & (4.33) & 0.074 & (4.32) \\
\hline & Slope & -0.191 & $(-2.79)$ & -0.155 & $(-2.53)$ & -0.045 & $(-2.66)$ & -0.115 & $(-2.82)$ & -0.112 & $(-2.79)$ \\
\hline & $R^{2}(\%)$ & 20.74 & & 15.83 & & 16.32 & & 16.42 & & 16.52 & \\
\hline \multirow{3}{*}{$\begin{array}{c}8 \\
\text { Quarters }\end{array}$} & Constant & 0.189 & (4.69) & 0.156 & $(4.51)$ & 0.108 & (3.65) & 0.147 & $(4.80)$ & 0.146 & $(4.81)$ \\
\hline & Slope & -0.382 & $(-3.55)$ & -0.315 & $(-3.35)$ & -0.064 & $(-2.13)$ & -0.234 & $(-3.36)$ & -0.227 & $(-3.34)$ \\
\hline & $R^{2}(\%)$ & 31.05 & & 24.74 & & 12.25 & & 25.69 & & 25.66 & \\
\hline \multirow{3}{*}{$\begin{array}{c}12 \\
\text { Quarters }\end{array}$} & Constant & 0.271 & $(4.82)$ & 0.225 & $(4.56)$ & 0.154 & (3.59) & 0.220 & (5.18) & 0.218 & $(5.21)$ \\
\hline & Slope & -0.531 & $(-3.56)$ & -0.442 & $(-3.33)$ & -0.085 & $(-2.02)$ & -0.352 & $(-3.92)$ & -0.342 & $(-3.92)$ \\
\hline & $R^{2}(\%)$ & 34.41 & & 28.04 & & 12.47 & & 33.23 & & 33.32 & \\
\hline \multicolumn{12}{|c|}{$\begin{array}{l}\text { Panel B: Future Market Portfolio Returns and the Volatility of SDFs } \\
\qquad R_{m t+1}=\alpha+\beta \sigma\left(M_{t}\right)+\varepsilon_{t+1}\end{array}$} \\
\hline & & \multicolumn{2}{|c|}{ Recursive } & \multicolumn{2}{|c|}{ Yogo } & \multicolumn{2}{|c|}{ Habit } & \multicolumn{2}{|c|}{$\begin{array}{c}\text { Recursive } \\
\text { Long }\end{array}$} & \multicolumn{2}{|c|}{$\begin{array}{l}\text { Yogo } \\
\text { Long }\end{array}$} \\
\hline \multirow{3}{*}{$\begin{array}{c}1 \\
\text { Quarter }\end{array}$} & Constant & 0.074 & $(2.27)$ & 0.040 & $(1.41)$ & 0.080 & (3.59) & 0.093 & $(3.42)$ & 0.092 & (3.43) \\
\hline & Slope & -0.155 & $(-1.73)$ & -0.055 & $(-0.65)$ & -0.086 & $(-3.31)$ & -0.199 & $(-2.92)$ & -0.194 & $(-2.91)$ \\
\hline & $R^{2}(\%)$ & 1.93 & & 0.28 & & 8.39 & & 7.16 & & 7.17 & \\
\hline \multirow{3}{*}{$\begin{array}{c}2 \\
\text { Quarters }\end{array}$} & Constant & 0.150 & (2.39) & 0.083 & $(1.51)$ & 0.159 & $(3.40)$ & 0.192 & (3.43) & 0.190 & (3.45) \\
\hline & Slope & -0.311 & $(-1.85)$ & -0.113 & $(-0.70)$ & -0.166 & $(-3.12)$ & -0.414 & $(-3.02)$ & -0.403 & $(-3.02)$ \\
\hline & $R^{2}(\%)$ & 3.14 & & 0.48 & & 12.55 & & 12.39 & & 12.45 & \\
\hline \multirow{3}{*}{$\begin{array}{c}4 \\
\text { Quarters }\end{array}$} & Constant & 0.329 & $(2.64)$ & 0.187 & $(1.74)$ & 0.289 & $(2.80)$ & 0.416 & $(3.52)$ & 0.412 & $(3.54)$ \\
\hline & Slope & -0.684 & $(-2.24)$ & -0.273 & $(-0.91)$ & -0.277 & $(-2.40)$ & -0.888 & $(-3.31)$ & -0.866 & $(-3.31)$ \\
\hline & $R^{2}(\%)$ & 5.52 & & 1.03 & & 12.79 & & 20.54 & & 20.70 & \\
\hline \multirow{3}{*}{$\begin{array}{c}8 \\
\text { Quarters }\end{array}$} & Constant & 0.637 & $(2.58)$ & 0.354 & $(1.88)$ & 0.517 & $(2.18)$ & 0.894 & (3.35) & 0.884 & (3.36) \\
\hline & Slope & -1.178 & $(-2.27)$ & -0.337 & $(-0.68)$ & -0.402 & $(-1.54)$ & -1.860 & $(-3.46)$ & -1.811 & $(-3.47)$ \\
\hline & $R^{2}(\%)$ & 4.28 & & 0.41 & & 7.10 & & 23.39 & & 23.49 & \\
\hline \multirow{3}{*}{$\begin{array}{c}12 \\
\text { Quarters }\end{array}$} & Constant & 0.787 & $(2.07)$ & 0.463 & $(1.71)$ & 0.733 & $(2.05)$ & 1.295 & $(2.98)$ & 1.282 & (2.99) \\
\hline & Slope & -1.065 & $(-1.43)$ & -0.070 & $(-0.10)$ & -0.454 & $(-1.24)$ & -2.501 & $(-2.90)$ & -2.433 & $(-2.91)$ \\
\hline & $R^{2}(\%)$ & 1.68 & & 0.01 & & 4.35 & & 20.35 & & 20.40 & \\
\hline
\end{tabular}


Table 3

\begin{tabular}{|c|c|c|c|}
\hline \multicolumn{4}{|c|}{$\begin{array}{l}\text { Panel A: Changes in Implied Volatility and Stochastic Discount Factors } \\
\qquad \frac{I V_{t}-I V_{t-1}}{I V_{t-1}}=\alpha+\beta M_{t}+\varepsilon_{t+1}\end{array}$} \\
\hline SDF & $\begin{array}{l}\text { Constant } \\
(\hat{\alpha})\end{array}$ & $\begin{array}{c}\text { Slope } \\
(\hat{\beta})\end{array}$ & $\begin{array}{l}R^{2} \\
(\%)\end{array}$ \\
\hline Habit & $\begin{array}{c}0.052 \\
(0.58)\end{array}$ & $\begin{array}{l}-0.002 \\
(-0.05)\end{array}$ & 0.0 \\
\hline Recursive & $\begin{array}{l}-0.777 \\
(-2.71) \\
\end{array}$ & $\begin{array}{l}0.889 \\
(3.10)\end{array}$ & 36.4 \\
\hline Yogo & $\begin{array}{l}-0.822 \\
(-2.66) \\
\end{array}$ & $\begin{array}{l}0.932 \\
(2.96) \\
\end{array}$ & 32.5 \\
\hline Recursive Long & $\begin{array}{l}0.191 \\
(0.74)\end{array}$ & $\begin{array}{l}-0.130 \\
(-0.43)\end{array}$ & 0.9 \\
\hline Yogo Long & $\begin{array}{l}0.188 \\
(0.71)\end{array}$ & $\begin{array}{l}-0.125 \\
(-0.41)\end{array}$ & 0.9 \\
\hline \multicolumn{4}{|c|}{$\begin{array}{l}\text { Panel B: Implied Volatility and Stochastic Discount Factors } \\
\qquad V_{t}=\alpha+\beta M_{t}+\varepsilon_{t+1}\end{array}$} \\
\hline SDF & $\begin{array}{c}\text { Constant } \\
(\hat{\alpha})\end{array}$ & $\begin{array}{c}\text { Slope } \\
(\hat{\beta})\end{array}$ & $\begin{array}{l}R^{2} \\
(\%)\end{array}$ \\
\hline Habit & $\begin{array}{l}0.275 \\
(8.10)\end{array}$ & $\begin{array}{l}0.001 \\
(0.08)\end{array}$ & 0.0 \\
\hline Recursive & $\begin{array}{l}0.073 \\
(1.63) \\
\end{array}$ & $\begin{array}{l}0.221 \\
(4.54) \\
\end{array}$ & 40.7 \\
\hline Yogo & $\begin{array}{l}0.068 \\
(1.39)\end{array}$ & $\begin{array}{l}0.225 \\
(4.13)\end{array}$ & 34.3 \\
\hline Recursive Long & $\begin{array}{l}0.170 \\
(2.77)\end{array}$ & $\begin{array}{l}0.114 \\
(1.36)\end{array}$ & 11.3 \\
\hline Yogo Long & $\begin{array}{l}0.169 \\
(2.76)\end{array}$ & $\begin{array}{l}0.115 \\
(1.38)\end{array}$ & 11.6 \\
\hline \multicolumn{4}{|c|}{$\begin{array}{l}\text { Panel C: Implied Volatility and the Volatility of the Stochastic Discount Factors } \\
\qquad \qquad V_{t}=\alpha+\beta \sigma\left(M_{t}\right)+\varepsilon_{t+1}\end{array}$} \\
\hline SDF & $\begin{array}{c}\text { Constant } \\
(\hat{\alpha})\end{array}$ & $\begin{array}{l}\text { Slope } \\
(\hat{\beta})\end{array}$ & $\begin{array}{l}R^{2} \\
(\%)\end{array}$ \\
\hline Habit & $\begin{array}{l}0.297 \\
(3.89)\end{array}$ & $\begin{array}{l}-0.031 \\
(-0.29)\end{array}$ & 0.3 \\
\hline Recursive & $\begin{array}{l}0.049 \\
(0.32)\end{array}$ & $\begin{array}{l}0.807 \\
(1.49)\end{array}$ & 10.2 \\
\hline Yogo & $\begin{array}{l}-0.075 \\
(-0.50)\end{array}$ & $\begin{array}{l}1.480 \\
(2.33)\end{array}$ & 17.4 \\
\hline Recursive Long & $\begin{array}{l}0.312 \\
(3.43)\end{array}$ & $\begin{array}{l}-0.147 \\
(-0.42)\end{array}$ & 0.5 \\
\hline Yogo Long & $\begin{array}{l}0.291 \\
(3.42)\end{array}$ & $\begin{array}{l}-0.062 \\
(-0.19)\end{array}$ & 0.1 \\
\hline
\end{tabular}

$1 /$ Robust $t$-statistics in parentheses

$I V_{t}$ is the implied volatility of ATM options at the last month of quarter $t, I V_{t-1}$ is the implied volatility at the last month of the previous quarter, $M_{t}$ is the stochastic discount factor for quarter $t$, and $\sigma\left(M_{t}\right)$ is volatility of the stochastic discount factor for quarter $t$. This volatility is estimated quarterly with five years of data. 
Table 4

\begin{tabular}{|c|c|c|c|}
\hline \multicolumn{4}{|c|}{$\begin{array}{l}\text { Panel A: Changes in Left-Tailed Probabilistic Mass Differences and Stochastic Discount Factors } \\
\qquad \frac{L T_{t}-L T_{t-1}}{L T_{t-1}}=\alpha+\beta M_{t}+\varepsilon_{t+1}\end{array}$} \\
\hline SDF & $\begin{array}{l}\text { Constant } \\
\quad(\hat{\alpha})\end{array}$ & $\begin{array}{l}\text { Slope } \\
(\hat{\beta})\end{array}$ & $\begin{array}{l}R^{2} \\
(\%)\end{array}$ \\
\hline Habit & $\begin{array}{l}0.287 \\
(1.24)\end{array}$ & $\begin{array}{l}-0.002 \\
(-0.01)\end{array}$ & 0.0 \\
\hline Recursive & $\begin{array}{l}-1.674 \\
(-1.88) \\
\end{array}$ & $\begin{array}{l}2.108 \\
(2.15)\end{array}$ & 25.8 \\
\hline Yogo & $\begin{array}{r}-1.716 \\
(-1.86) \\
\end{array}$ & $\begin{array}{l}2.139 \\
(2.10) \\
\end{array}$ & 21.6 \\
\hline Recursive Long & $\begin{array}{r}1.130 \\
(1.91)\end{array}$ & $\begin{array}{l}-0.933 \\
(-1.42)\end{array}$ & 9.9 \\
\hline Yogo Long & $\begin{array}{l}1.118 \\
(1.87)\end{array}$ & $\begin{array}{l}-0.914 \\
(-1.38) \\
\end{array}$ & 9.8 \\
\hline \multicolumn{4}{|c|}{$\begin{array}{l}\text { Panel B: Left-Tailed Probabilistic Mass Differences and Stochastic Discount Factors } \\
\qquad L T_{t}=\alpha+\beta M_{t}+\varepsilon_{t+1}\end{array}$} \\
\hline SDF & $\begin{array}{l}\text { Constant } \\
\quad(\hat{\alpha})\end{array}$ & $\begin{array}{l}\text { Slope } \\
(\hat{\beta})\end{array}$ & $\begin{array}{l}R^{2} \\
(\%)\end{array}$ \\
\hline Habit & $\begin{array}{l}0.028 \\
(4.22)\end{array}$ & $\begin{array}{l}-0.001 \\
(-0.52)\end{array}$ & 0.3 \\
\hline Recursive & $\begin{array}{l}-0.012 \\
(-1.42) \\
\end{array}$ & $\begin{array}{l}0.042 \\
(4.28)\end{array}$ & 40.6 \\
\hline Yogo & $\begin{array}{r}-0.014 \\
(-1.41) \\
\end{array}$ & $\begin{array}{r}0.043 \\
(3.93) \\
\end{array}$ & 34.8 \\
\hline Recursive Long & $\begin{array}{l}0.004 \\
(0.33) \\
\end{array}$ & $\begin{array}{l}0.024 \\
(1.40) \\
\end{array}$ & 12.4 \\
\hline Yogo Long & $\begin{array}{l}0.004 \\
(0.31)\end{array}$ & $\begin{array}{l}0.024 \\
(1.43)\end{array}$ & 12.8 \\
\hline \multicolumn{4}{|c|}{$\begin{array}{l}\text { Panel C: Left-Tailed Probabilistic Mass Differences and the Volatility of the Stochastic Discount } \\
\qquad \begin{array}{l}\text { Factors } \\
\qquad L T_{t}=\alpha+\beta \sigma\left(M_{t}\right)+\varepsilon_{t+1}\end{array}\end{array}$} \\
\hline SDF & $\begin{array}{l}\text { Constant } \\
\qquad(\hat{\alpha})\end{array}$ & $\begin{array}{l}\text { Slope } \\
(\hat{\beta})\end{array}$ & $\begin{array}{l}R^{2} \\
(\%)\end{array}$ \\
\hline Habit & $\begin{array}{l}0.034 \\
(2.32)\end{array}$ & $\begin{array}{l}-0.011 \\
(-0.56)\end{array}$ & 1.2 \\
\hline Recursive & $\begin{array}{c}-0.018 \\
(-0.65) \\
\end{array}$ & $\begin{array}{l}0.158 \\
(1.55) \\
\end{array}$ & 10.8 \\
\hline Yogo & $\begin{array}{l}-0.041 \\
(-1.55)\end{array}$ & $\begin{array}{l}0.282 \\
(2.49)\end{array}$ & 17.4 \\
\hline Recursive Long & $\begin{array}{l}0.032 \\
(1.79) \\
\end{array}$ & $\begin{array}{l}-0.026 \\
(-0.38) \\
\end{array}$ & 0.4 \\
\hline Yogo Long & $\begin{array}{l}0.028 \\
(1.68)\end{array}$ & $\begin{array}{l}-0.009 \\
(-0.14)\end{array}$ & 0.1 \\
\hline
\end{tabular}

$1 /$ Robust $t$-statistics in parentheses

$L T_{t}$ is the difference between the probabilistic mass assigned by the risk-neutral distribution and the riskadjusted distribution for the $10 \%$ left-tail at the last month of quarter $t, L T_{t-1}$ is the same difference at the last month of the previous quarter, $M_{t}$ is the stochastic discount factor for quarter $t$, and $\sigma\left(M_{t}\right)$ is volatility of the stochastic discount factor for quarter $t$. This volatility is estimated quarterly with five years of data. 
Figure 1

Hansen-Jagganathan Volatility Bound 1963-2003

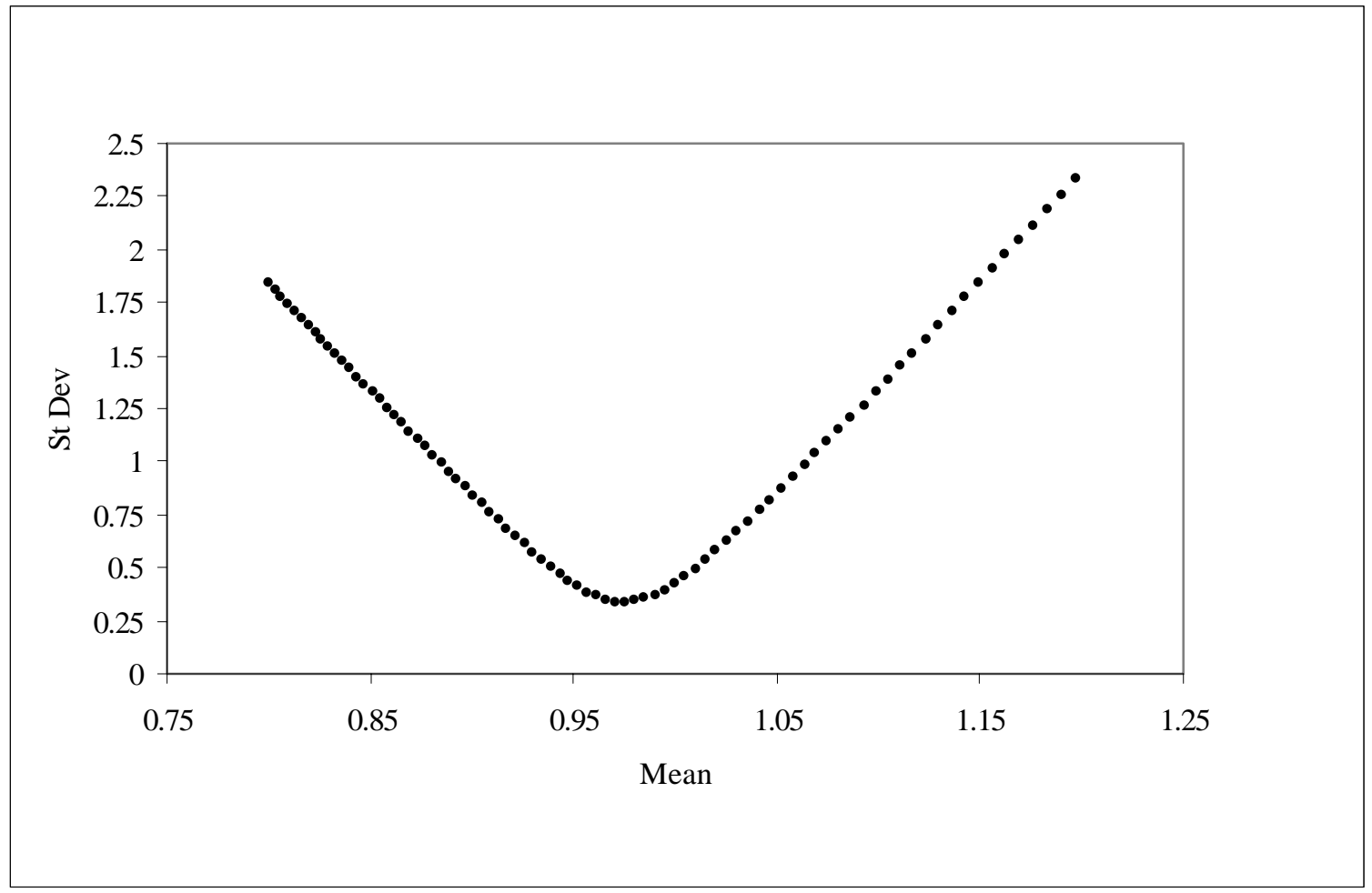


Figure 2

Hansen-Jagganathan Volatility Bound by Overlapping Five-Year Sub-periods 1963-2003

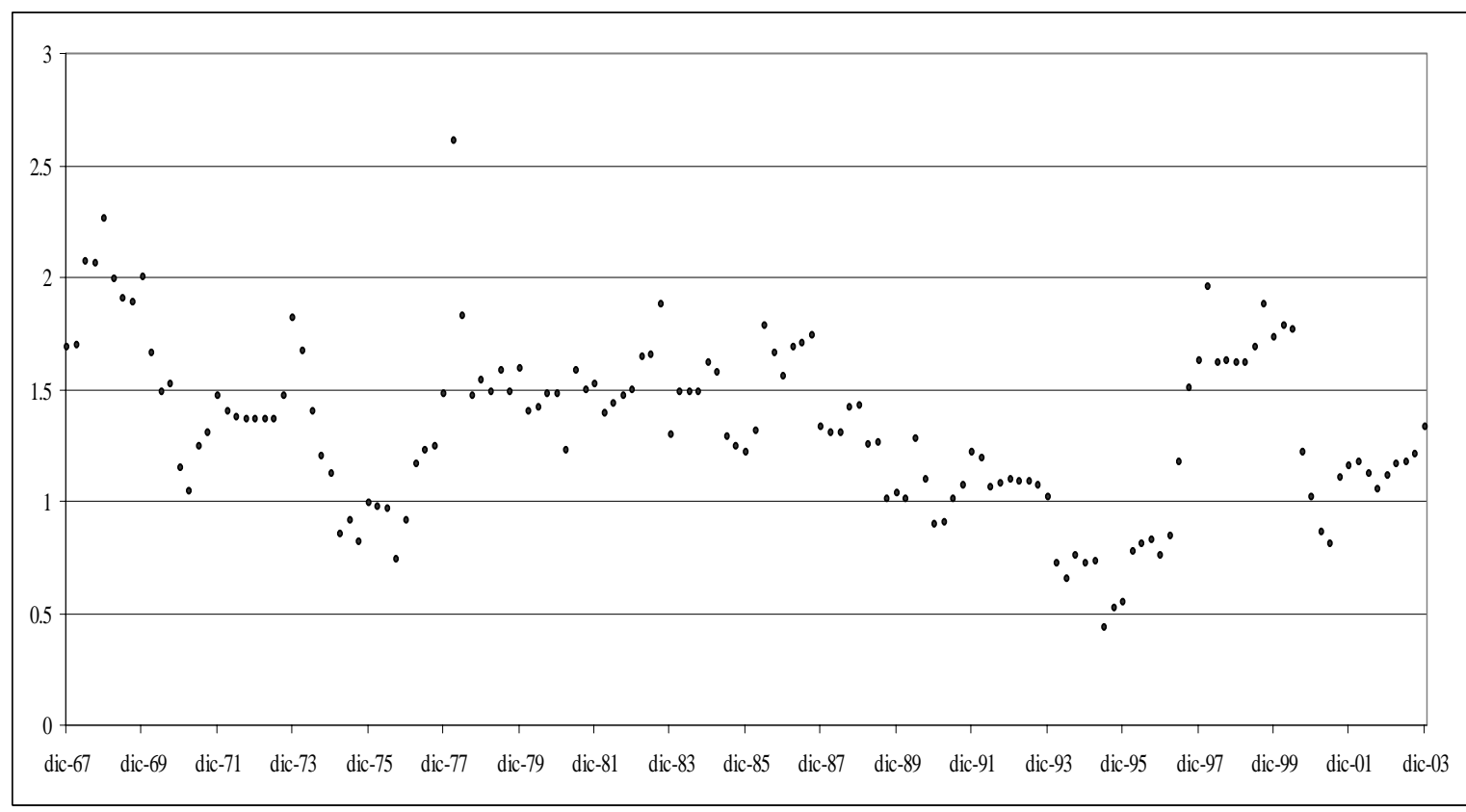

- HJ Bound

Market Recessions

$\square$ Macroeconomic Recessions 
Figure 3

Hansen-Jagganathan Volatility Bound and Stochastic Discount Factor Models 1963-2003

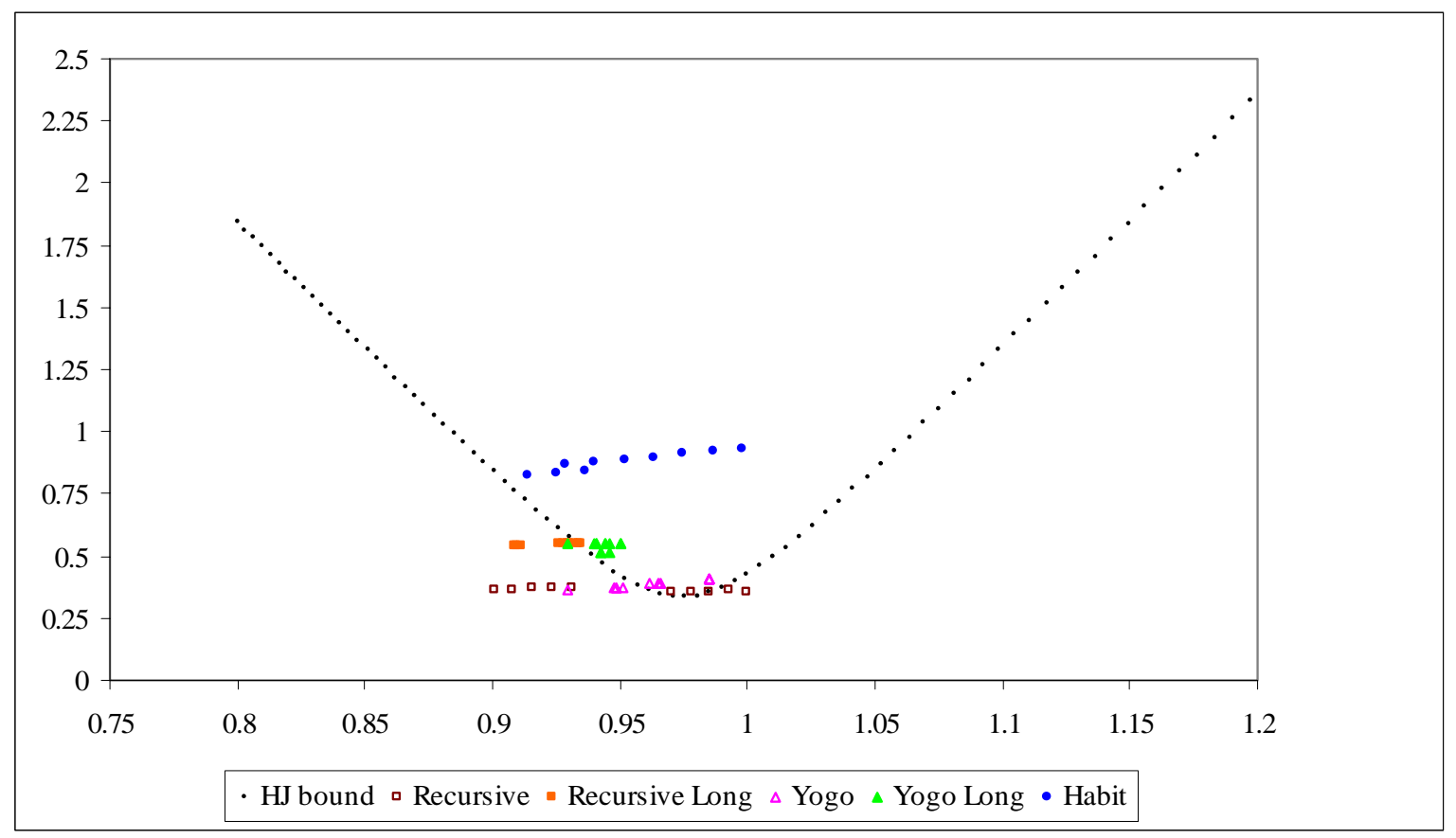


Figure 4

Stochastic Discount Factors during Market and Macroeconomic Recessions 1963-2003

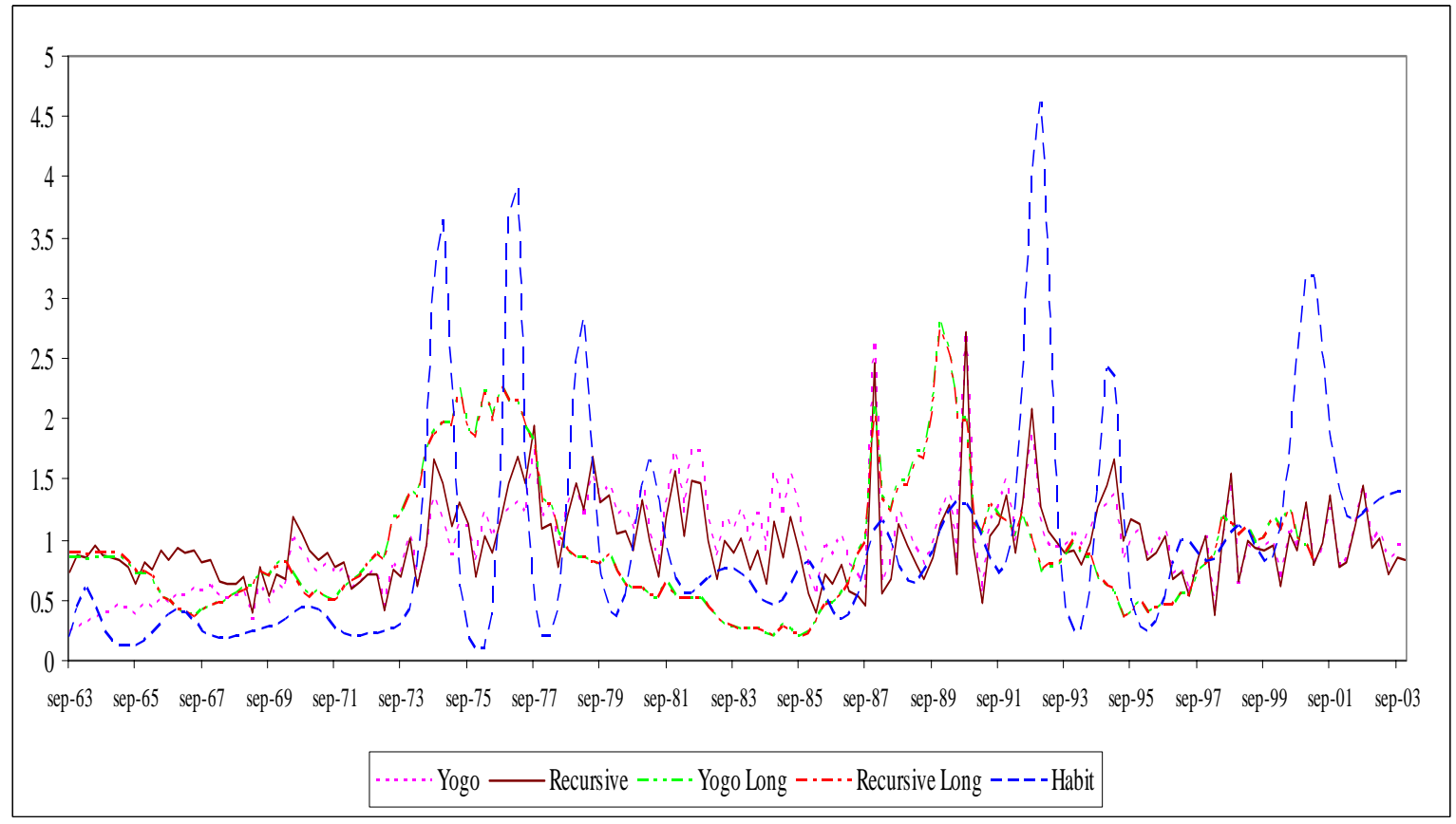


Figure 5

Stochastic Discount Factor Volatilities during Market and Macroeconomic Recessions

1963-2003

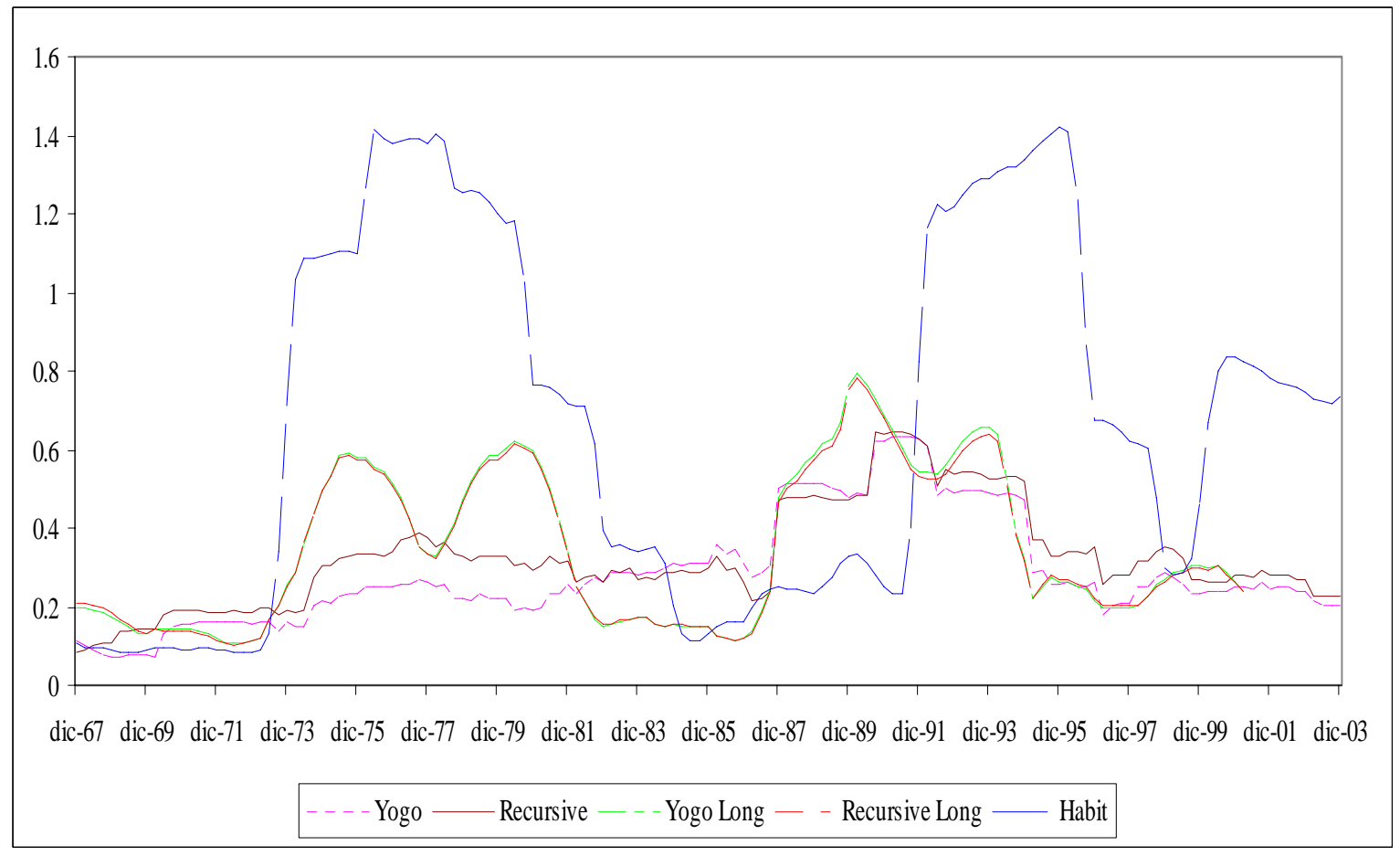


Figure 6

Capturing Uncertainty: Left-tail Probability Difference between Risk-neutral and Risk-adjusted Density Functions and Implicit Volatility

1996-2004

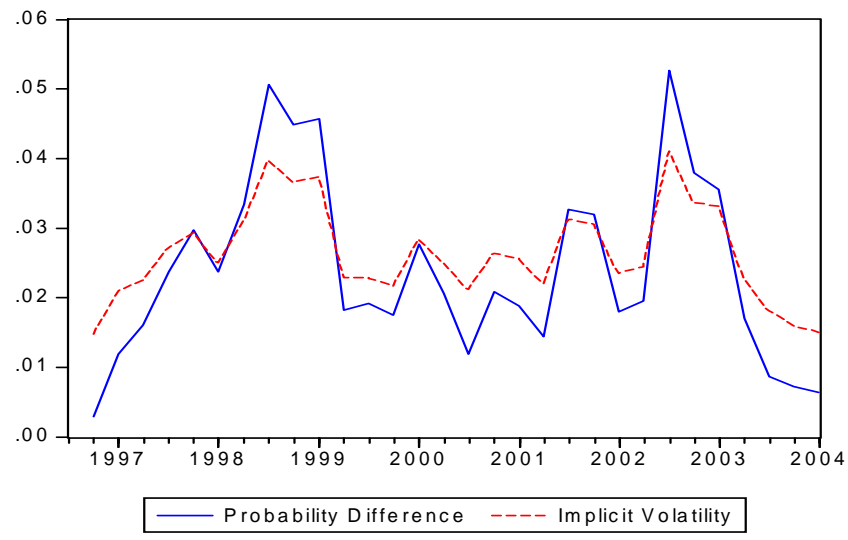


Figure 7

Hansen-Jagannathan Volatility Bound by Overlapping Five-Year

Sub-periods for the US Market

1963-2003

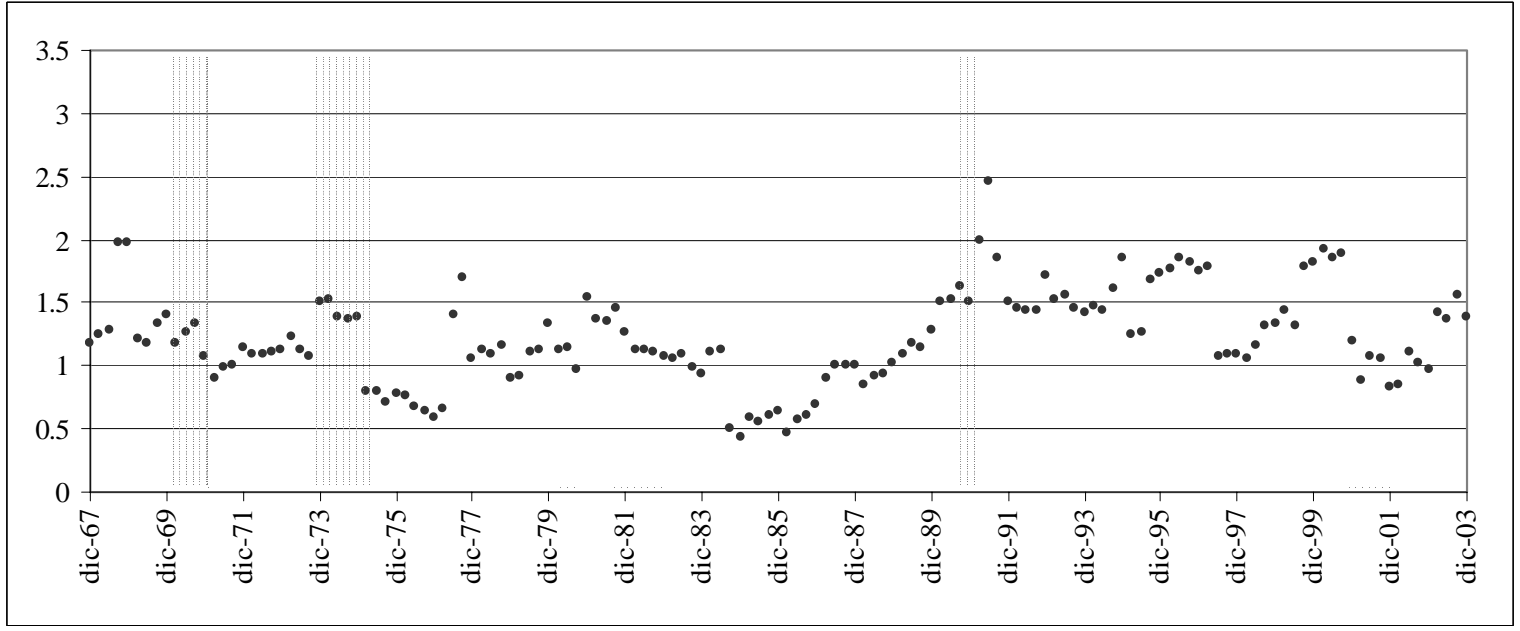


Figure 8

Stochastic Discount Factors during Macroeconomic Recessions for the US Market 1963-2003

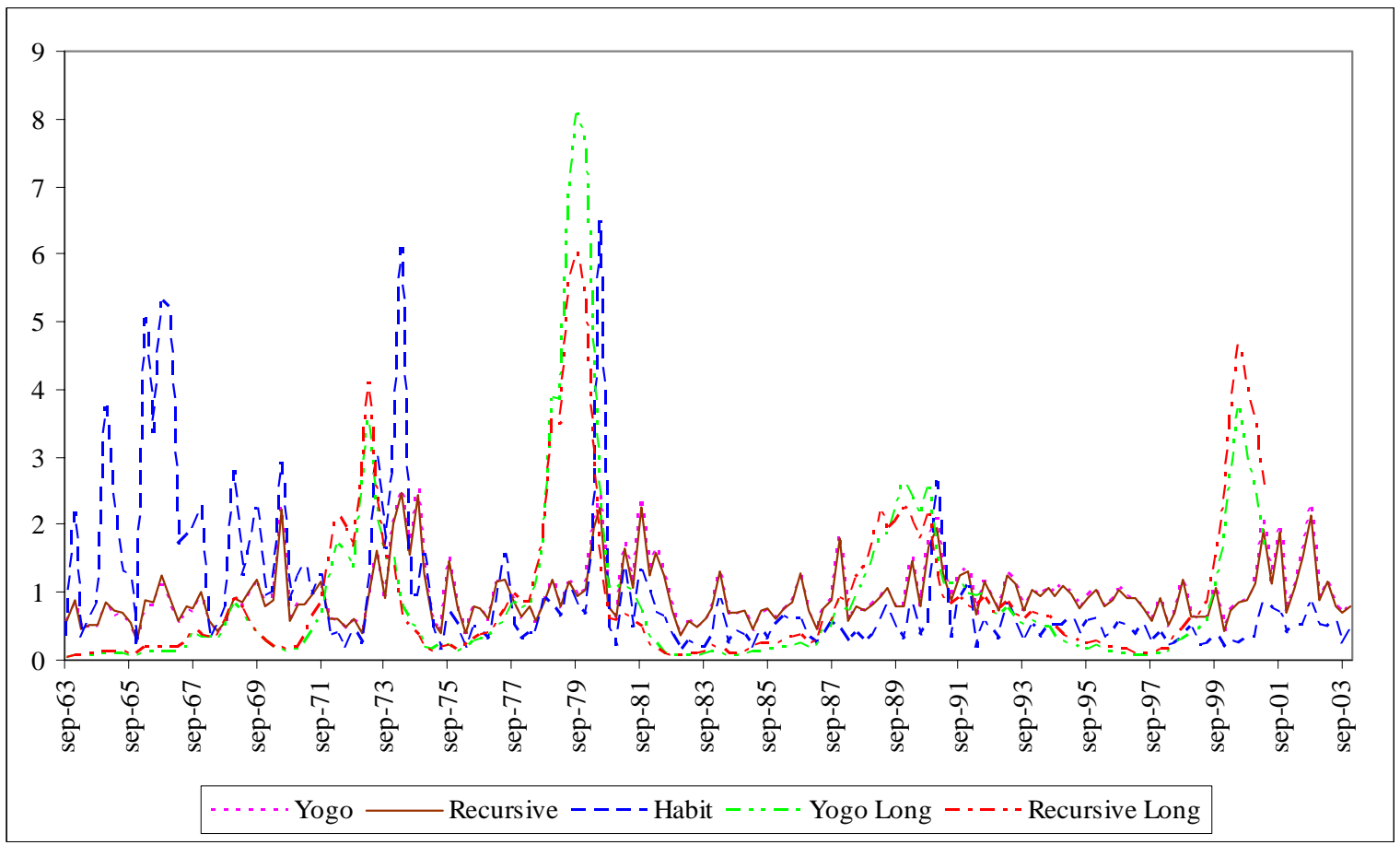


Figure 9

Stochastic Discount Factor Volatilities during Macroeconomic Recessions for the US Market

1963-2003

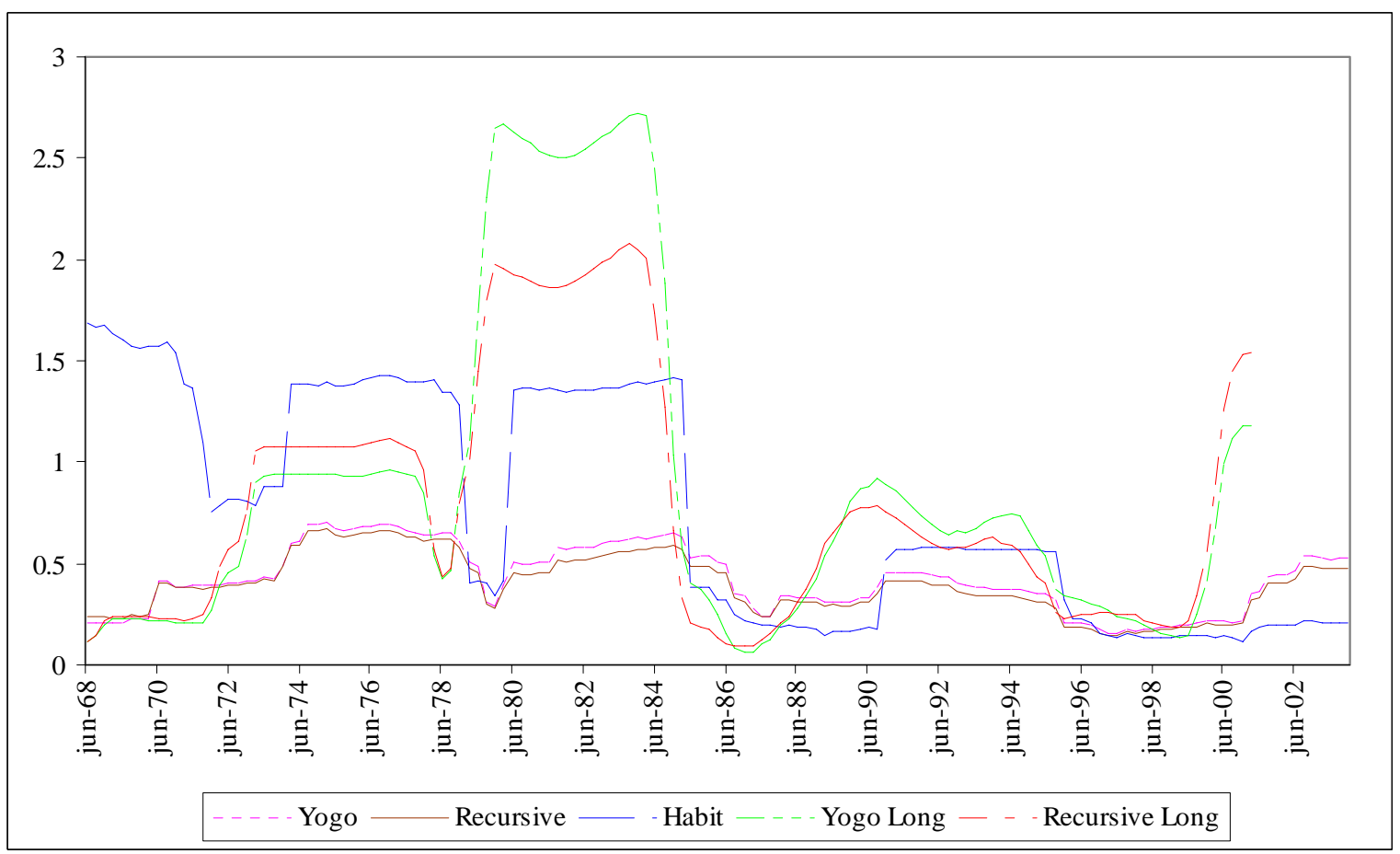

